\title{
SIGNOS PELA LUTA FEMINISTA
}

\author{
SIGNS FOR THE FEMINIST STRUGGLE
}

\begin{abstract}
RESUMO
Apresenta-se, neste artigo, a problemática da linguagem no campo dos Estudos de Gênero e do movimento feminista como territórios de ressignificações da realidade das mulheres, circunscrita no contexto das violências que têm se fortalecido e dificultado cada vez mais a luta pelos seus direitos. Problematiza-se os próprios signos que compõem esse universo, no qual os sentidos impostos pela ideologia dominante apregoam as tradicionais dicotomias que insistem em ignorar as causas do movimento feminista e desvalorizar a sociologia do debate sobre desigualdade de gênero. Argumentos como os de Boaventura de Souza Santos (2013) e Heleieth Saffioti (2001) fundamentam as ideias propostas, bem como são alinhavadas a conceitos do campo da Teoria Feminista. Com tal proposição, arremata-se a discussão com a defesa de que há muita luta pelo caminho, mas urgente é a desconstrução das ideologias de dominação.
\end{abstract}

Palavras-chave: Movimento feminista. Estudos de gênero. Linguagem. Signos.

\section{ABSTRACT}

This paper presents the problematic of language in the Gender Studies debate and the feminist movement as areas of ressignification of the reality of women, circumscribed in the context of the violence that has been strengthened and increasingly difficult to fight for their rights. The signs that compose this universe are problematized in which the senses imposed by the dominant ideology are haunting the traditional dichotomies that insist on ignoring the causes of the feminist movement and devaluing the sociology of the debate on gender inequality. Arguments such as those of Boaventura de Souza Santos (2013) and Heleieth Saffioti (2001) base the ideas proposed, as well as are aligned with concepts in the field of Feminist Theory. With this proposition, the argument is concluded with the defense that there is a lot of struggle for the way, but urgency is the deconstruction of the ideologies of domination.

Key-words: Feminist movement.Gender studies. Language.Signs.

Nos movimentos sociais brasileiros, sobretudo os feministas, a palavra "lugar" tem ganhado relevo ao compor discursos de resistência e fundamentar a necessária luta política dos grupos minoritários diante do contexto da desigualdade. O termo, que veio do latim locus, já não cabe unicamente na enciclopédica definição de

Mirele C. W. Jacomel

Instituição: Instituto Federal do Paraná - IFPR. Email: mirele.jacomel@ifpr.edu.br 
lugar ou posição, acepção restrita à sintaxe de olhar conservador. E, sim, adquiriu o próprio sentido da luta pela liberdade, emancipação, autonomia, resistência, dor, reconhecimento e tantos outros "lugares" pelos quais a militância das mulheres já passou. Mas esse mesmo lugar de tantas vivências e experiências advindas da luta feminista também carrega signos da consequência, como as marcas que as mulheres levam consigo, nos seus corpos, na sua identidade. Assim, os corpos da resistência feminista passam à inscrição no universo patriarcal, como a representatividade de um cenário somente onde a luta se torna legítima. Inevitavelmente, nesse campo da luta das mulheres, engendra-se a luta contra o masculino-dominador, que sempre se revelou austero ao ter seu comportamento questionado. Instaura-se nessa seara a violência de gênero abrangendo vítimas, quase sempre mulheres, como que num exercício da função patriarcal, argumento revelado na conduta dos homens que estariam culturalmente autorizados a tal função social, para punir aquilo que representaria, nos termos de Heleieth Saffioti (2001), um desvio: "a execução do projeto de dominação-exploração da categoria social homens exige que sua capacidade de mando seja auxiliada pela violência" (2001:115).

As manifestações de resistência adquirem múltiplas performances na fala e a linguagem propositalmente externa todos esses emblemas, por isso a história das mulheres é marcada também por uma constante luta pelo "lugar de fala", ideia que se sustenta na subjetividade, na existência e na diferença. Isto é, no campo da militância feminista, como movimento histórico, permanente, a mulher precisa lutar para ser ouvida, atitude que deveria minimamente estar subentendida por sermos todos seres humanos e desenvolvidos em nossa linguagem. Exigir, portanto, ser ouvida e, assim, assegurar um lugar na teia discursiva, é antes de mais nada, também uma luta pela sua liberdade. Marcia Tiburi, em seu livro Feminismo em comum - para todas, todes e todos (2018), sintetiza claramente tal concepção ao afirmar que "o lugar de fala é fundamental para expressar a singularidade e o direito de existir” (2018: 115).

Simples seria se a razão da desigualdade estivesse no âmbito da linguagem. Esta reproduz o status quo das hegemonias. No entanto, há uma escancarada desigualdade socioeconômica que assola a população brasileira, justificando as classes e os movimentos sociais de combate à desigualdade. A mulher das classes economicamente desfavorecidas já nasce no contexto de uma guerra invisível, mas que é capaz igualmente de destruir soldados, calar e manipular povos, e subordinar adversários. Essa guerra é cultural.

Uma síntese das desigualdades que tomaram conta das populações economicamente desfavorecidas no Brasil está inscrita nas estatísticas que frequentemente mostram o lugar que a mulher vem ocupando. 51\% das mulheres não concluíram a Educação Básica em 2017; há mais de 68 mil mães adolescentes, em idade escolar; $48 \%$ das mulheres não possuem empregos formais ou estão desempregadas; além dos índices relacionados à violência, como as 606 mulheres que são fisicamente agredidas por dia; as 60.018 mulheres que foram estupradas em 2017 - casos registrados; e os mais de mil e cem casos de feminicídio no mesmo ano (FGV, 2019). Esses números, por si, já endossam a luta pela liberdade da 
mulher, todavia, não se observa discernimento quando grupos fundamentalistas proliferam discursos de extenuação dos movimentos feministas, sob o argumento de que as mulheres já conseguiram o que havia para ser conquistado. Percebe-se, nesse contexto, que a palavra liberdade não tem sido compreendida em sua real significação. No limite, o que muitos discursos de base patriarcal entendem é que as mulheres são geograficamente livres, pois estão autorizadas a sair, relacionaremse, podem trabalhar, assumir cargos, participar de eventos, circular pelos espaços públicos. Novamente cabe pontuar que a linguagem possibilita ressignificar o mundo e a busca pela liberdade extrapola tempos e espaços. O que se almeja é o lugar de liberdade, é o reconhecimento da sua diferença, é o empoderamento de seu corpo e voz. É uma guerra por direitos.

A premissa estabelecida pelos embrionários temas que fervilhavam a mente de estudiosos e pesquisadores na década de 1970 abriu caminho para um movimento mais sutil, porém mais radical no campo epistemológico, balizando-se por teorias interpretativas, formações discursivas e análises históricas como forma de ressignificação do papel da mulher. A tão estudada Crítica Feminista, nascida do contexto Pós-estruturalista, insistia no desnudamento das práticas hegemônicas determinadas pela cultura patriarcal. Todavia, hoje, o que pode se conceber como um avanço no mesmo campo teórico, configura, ao mesmo tempo, um diálogo muito maior com a realidade, lançando mão da realidade dos movimentos como principal laboratório de análises. A empiria como método está muito mais presente no século XXI, território de onde jamais podem ser excluídos os aspectos político e econômico, pois são indissociáveis do objeto analisado. A despeito desse avanço, há, no Brasil, um perfil tímido para os grupos que se comprometem com a Crítica Feminista, diferente dos estudos cada vez mais consolidados do marxismo. Heloísa Buarque de Hollanda pontua de modo interessante essa conduta:

No caso do Brasil, as coisas não passam com facilidade. Há como que um desconforto, um tipo muito específico de imprecisão quando se formam grupos e núcleos de estudo sobre a mulher. Pode-se perceber, por exemplo, uma enorme dificuldade na auto-identificação como feministas, inclusive por parte das profissionais liberais, intelectuais, artistas ou políticas com livre acesso a espaços públicos e centros de decisão. Esta imprecisão, se não me engano, diz respeito, de forma bastante direta, aos mitos que regem a lógica das relações de gênero entre nós e, de forma mais geral, à especificidade das relações de poder no Brasil (HOLLANDA, 2003: 16).

Qualquer estudo sob a concepção de sociedade democrática e mais justa, que se incumbe da luta pelos direitos de todos, é capaz de desnudar as complexidades das tessituras culturais. Não faltam exemplos, principalmente os propagados nas mídias populares, para ilustrar a crise social do Brasil. Há diariamente casos que remetem 
principalmente à violência, motivo pelo qual o país está entre os dez mais violentos no mundo (OMS, 2018). Em outras palavras, entende-se que o enraizamento da cultural de dominação e sua insistente manutenção tem criado novas ferramentas, mais agressivas, em tentativas de permanecer no poder. Então, observa-se que a cada novo ataque à liberdade da mulher, elas precisam reinventar seus discursos, sua linguagem e suas lutas para não compor os números supracitados. Cabe aqui, naturalmente, salientar a importância do domínio sobre a linguagem para o empoderamento das mulheres, para a consolidação do movimento de luta, de onde surgem as formas de enfrentamento face aos constantes projetos criados para a manutenção do patriarcalismo. A título de exemplo, ao discutir e vivenciar as práticas da militância, surge o signo da proteção compartilhada, representada pela palavra sororidade e que, a partir de então, passa a ser uma nova bandeira para o movimento.

Diante dessa realidade, sobretudo pela ótica dos direitos humanos da mulher, nota-se que nem mesmo os dispositivos legais de punição aos agressores estão funcionando enquanto medidas de proteção, tampouco constituem o estado de segurança criado com tal intuito. Paira claramente pela sociedade uma cultura do abuso, que, de certa forma, permite desincumbirem-se os cidadãos de cumprir as leis brasileiras. Há também um estado autoritário que age de forma negligente por não investir naquilo que é direito das mulheres.

Caberia à ciência trazer a tona esse debate? Categoricamente diríamos que sim, o lugar da ciência é também o de um movimento social,de bases empíricas, o que possibilita problematizar a sociedade brasileira em seus organismos sociais. Cabem às pesquisas colaborar para a disseminação dos complexos fatores da violência por meio de análises que fogem ao sensacionalismo, mas que examinam o problema da desigualdade como categoria social. A ciência também pode provocar a sociedade para que sejam produzidas políticas de igualdade de gênero.

Na década de 1990, a professora Maria Consuelo Campos propõe analisar a categoria gênero no contexto do sistema sexo-gênero, onde são construídas as relações entre homens e mulheres. Por meio desse sistema, seria possível identificar condutas masculinas e femininas e compreender como se dá o seu fortalecimento no imaginário da população. Trata-se de um território organizado por dicotomias que estabeleceram algumas relações de oposição e incontiguidade, a exemplo das tradicionais dicotomias, como os visados universos feminino e masculino, ou a oposição entre público e privado, razão e emoção, entre outros. A proposta de análise ainda é capaz de explicar os fatores que impossibilitam a superação da desigualdade. O sistema sexo-gênero é cultural.

Mas é também possível acrescentar à discussão o fator subjetividade. Nesse campo de batalhas, as mulheres fortaleceram o signo da força em suas identidades. Já não são admitidos adjetivos como fúteis e frágeis, ou mesmo padrões de beleza, mesmo porque as próprias mulheres já se deram conta de que tais condições eram, muitas vezes, circunstanciadas para lhes manter alienadas sob o domínio do patriarcado. É possível afirmar, portanto, que nos últimos anos o sistema sexo-gênero deixou de ser apenas algo complexo que definia as identidades de gênero, e se tornou um campo de 
batalhas onde as mulheres se inscrevem como militantes de uma causa maior - que é a luta contra a violência.

E são múltiplas as formas de violência que têm assombrado a vida das mulheres. Embora alguns críticos midiáticos aleguem que a violência sempre existiu e que agora ganharam os noticiários, não se pode descartar que a essência da desigualdade tem explicação no desejo de poder, no ato possessivo, na necessidade de se prevalecer sobre o outro, fatores que vão dando materialidade à violência. $\mathrm{O}$ desejo de poder transpôs o campo econômico e passou a habitar uma simples relação social. Por esse viés, ocorre uma submissão paradoxal, de que fala Pierre Bourdieu (2007), resultante da violência simbólica, insensível e invisível até mesmo às próprias vítimas. São tipos de violência que se exercem "essencialmente pelas vias puramente simbólicas da comunicação e do conhecimento, ou, mais precisamente, do desconhecimento, do reconhecimento, ou, em última instância, do sentimento" (2007: 7-8). Essa seria a lógica da dominação, nos termos de Bourdieu, dimensão simbólica da dominação masculina.

Sem dúvidas, não é possível fragmentar o tecido social para analisar isoladamente a desigualdade de gênero. Sujeitos históricos e culturais que são, todos estão situados em tempos e espaços cujos contextos produzem efeitos sobre as relações. A violência física, por exemplo, está muito mais presente nas populações mais pobres, assim como a opressão paira sobre todas as classes. Por outro lado, mulheres de diferentes níveis econômicos sofrem assédio no trabalho ou submetemse ao silenciamento para não se deslocarem da sua zona de conforto. Entretanto, enquanto objeto de análise, é fundamental dissecar os discursos formados no território patriarcal e procurar entender seus estímulos perante os diferentes setores da sociedade.

Ao passo que as lutas pela igualdade de gênero multiplicam-se pelo país por meio de movimentos sociais organizados, ações com finalidade inclusiva se subdividem e são postas em prática na tentativa de amenizar as desigualdades. Desde a criação de setores públicos até a proposição de novos dispositivos legais, todas as ações implicam em uma distribuição orçamentária que, muitas vezes, não agrega a concordância de todos os cidadãos. A política de expansão e interiorização da educação federal, por exemplo, ancora-se no plano de um governo mais democrático que visa recuperar débitos de formação e levar à população a justiça social. Todavia, parece ser, atualmente, um projeto interrompido, com ameaças de redução da estrutura, além de um desgastante discurso de enxugamento da formação básica pela qual toda pessoa precisa passar.

Foi naquele percurso que surgiu o Programa Mulheres Mil (BRASIL, s/d). Implantado inicialmente na região do Nordeste brasileiro, o programa tinha a meta de incluir mulheres no contexto educacional, oferecendo-lhes formação técnica e profissional para que pudessem empreender e desenvolver uma profissão. A lógica do Mulheres Mil era aproveitar os arranjos produtivos locais e reconhecer saberes que as mulheres já possuíam, convergindo tudo para a sua subsistência econômica. Uma proposta louvável que se estendeu ao país por meio dos Institutos Federais e 
formou em cada estado em torno de mil mulheres. Como se tratava de uma proposta vinculada a um programa de governo, houve mudanças na pactuação dos recursos investidos na formação dessas mulheres e, inevitavelmente, a proposta perdeu sua finalidade primeira. Esse é só mais um claro exemplo de que educação é investimento social e que apenas projetos de sociedade mais justa e democrática são capazes de produzir essas transformações.

Os impactos que os movimentos sociais causam nas políticas públicas também são aspectos importantes para se destacar. A manifestação social é um legítimo termômetro que indica a necessidade de medidas para sanar os conflitos. Daí a salutar causa feminista como medida para os líderes políticos observarem os problemas da sociedade.

No que diz respeito à educação, também se cumpre o papel social de colocar o ensino, a pesquisa e a extensão em evidência para contribuir com a transformação social. Cada vez mais surgem linhas de pesquisa, projetos e ações que marcam o território da luta pela igualdade de gênero, e, assim, fortalecem os discursos que visam à superação das formas de violência contra a mulher. A ciência pode, sem dúvidas, transformar a sociedade.

Boaventura de Souza Santos, no capítulo que divide a obra Direitos Humanos, Democracia e Desenvolvimento, apresenta um conjunto de teorias que desvelam a complexidade da luta pelos direitos. Segundo o autor, há tensões nesse campo que pressupõem duas forças quase opostas. Em sua análise, existe uma tensão entre o reconhecimento da igualdade e o reconhecimento da diferença, tendo como pano de fundo os direitos humanos eurocêntricos. O princípio da igualdade está estabelecido perante a lei, ou seja, todos são iguais juridicamente. Ocorre que grupos sociais que sofrem discriminação e exclusão, como é o caso das feministas, se organizaram para colocar em pauta a violência que sofrem e para discutir os critérios dominantes de igualdade e diferença. Todavia, a luta pela igualdade de direitos implica na ideia de universalismo. Sendo assim, conforme Santos,

a luta contra a discriminação e exclusão deixou de ser uma luta pela integração e pela assimilação na cultura dominante e nas instituições suas subsidiárias, para passar a ser uma luta pelo reconhecimento da diferença, pela consequente transformação da cultura das instituições de modo a separar as diferenças (a respeitar) das hierarquias (a eliminar) que atavicamente lhe estavam referidas (2013: 79).

Esse ponto de vista, sob o qual Santos formulou sua tese das tensões, adentra o interior dos debates da desigualdade de gênero, como fatores que muitas vezes passam imperceptíveis sobre o tema, invalidando alguns complexos conceitos que subjazem as práticas da desigualdade. Por esse viés, é possível dizer que a igualdade na diferença, expressão bastante utilizada na primeira década do século XXI em nosso país, é tão fundamental enquanto categoria de análise, quanto bandeira dos 
movimentos sociais feministas. Ao mesmo tempo, desconstruir hierarquias de natureza patriarcal também deve fazer parte dessa luta pelos direitos, visto que um projeto de sociedade no modelo eurocêntrico não sucumbe aos interesses das classes consideradas minoritárias, tampouco tem como intuito possibilitar que as mulheres atinjam os mesmos espaços e lugares que os homens.

Mais do que em qualquer outro tempo, a mulher precisa empoderar-se e ocupar os lugares que pertencem à humanidade, que pertencem aos homens e mulheres, sem distinção. Público ou privado, cargos no comércio e na indústria, o trabalho com a terra, a militância sindical, a academia, a ciência entre tantas outras atuações são os lugares que a mulher deveria estar presente, nas mesmas condições de qualquer outro cidadão. Giulani, há quase duas décadas, já havia enfatizado a importância da militância da mulher e sua presença em todos os lugares:

As mulheres estão conscientes de que deverão vencer dois novos desafios: no nível prático, deverão atuar nos espaços do sindicato, da empresa e da família; no nível político e cultural, deverão defender mudanças no âmbito das relações interpessoais e de gênero que são bastante diferentes nos três espaços (GIULANI, 2001: 654).

Há, todavia, uma espécie de morosidade que afeta a saída das mulheres da sua zona de conforto, ou, ainda, que impedem o empoderamento das mulheres. Isso demonstra que a cultura é um dispositivo de poder sobre as estruturas sociais.

Judith Butler, que entende os discursos como um instrumento de opressão, ou seja, como modos de induzir e incitar os sujeitos a construírem, pela linguagem, uma ideia de si próprios. A ideia é a de tratar o gênero como efeito - e não causa - de instituições, discursos e práticas. Tal categoria é tratada não como um atributo que os sujeitos possuem, mas como um discurso sobre suas identidades.

Em termos culturais, grande parte das mulheres já percebeu que as relações de gênero são práticas construídas ao longo da história da humanidade, assim como as relações binárias, as relações de poder e as construções identitárias. Estão cientes, nesse sentido, de que podem ser desconstruídas em favor da igualdade social. De acordo com Bourdieu,

a ordem social funciona como uma imensa máquina simbólica que tende a ratificar a dominação masculina sobre a qual se alicerça: é a divisão social do trabalho, distribuição bastante estrita das atividades atribuídas a cada um dos sexos, de seu local, seu momento, seus instrumentos; é a estrutura do espaço, opondo o lugar de assembléia ou de mercado, reservados aos homens, e a casa, reservada às mulheres; [...] O mundo social constrói o corpo como realidade sexuada e como depositário de princípios de visão e de divisão sexualizantes (2007: 18). 
Com essa visão de Bourdieu, legitima-se o que Giulani (2001) relata em seu estudo sobre o nível prático e o nível político das relações de gênero no campo de trabalho. As distribuições desiguais de trabalho sustentam o paradigma da dominação, que enfoca a diferença biológica do homem e da mulher. Fica claro entender que as diferenças sexuais se explicam naturalmente pela biologia dos corpos, que determinam a diferença social construída entre os gêneros. Considerese, ainda, que apesar de uma mulher ter presidido a nação brasileira, o projeto de impedimento se fortaleceu, entre outras medidas, pela rejeição que o país possui com relação à igualdade, ao respeito e à justiça social. Por isso a mulher ainda ocupando os bastidores. E quando decide ocupar outros espaços, enfrenta um verdadeiro campo de batalhas.

O papel político da mulher na atualidade está fundamentado nos movimentos feministas que ajudaram a construir a história do fim do século XX e início do século XXI. A dimensão da força feminina é vista nas instituições de ensino, secretarias, organizações que tratam dos diversos assuntos que possuem como tema a mulher. Ao salientar a importância dos debates acerca das desigualdades de gênero, Rosaldo (1979: 33) observou que "a mulher pode ser importante, poderosa e influente, mas parece que em relação ao homem de sua idade e de seu status social, a mulher em todo o lugar carece de poder reconhecido e valorizado culturalmente”. As diferentes formas de representação da mulher, seja nos círculos sociais concretos, seja na tratativa que os veículos de informação dão às questões do universo feminino, são co-responsáveis pela dominação masculina. A mídia contribui fortemente para a reprodução de imagens que perpetuam as oposições advindas do paradigma razão $\mathrm{x}$ emoção. A mídia impõe uma linguagem masculina e ofensiva, ignorando a história e o empoderamento da mulher.

Outra observação pertinente está no discurso do "politicamente correto", expressão que surge na década de 1990 com a mídia enfatizando a possibilidade de ascensão das mulheres e outras vozes oriundas da periferia. Com isso, pretendeu-se criar o sentido de aceitação do outro ao mesmo tempo, mas longe de uma perspectiva de equidade. Contudo, a própria mulher continua a ser depositária dos sentidos da relação dominante $\mathrm{x}$ dominado e seu corpo torna-se objeto de opressão, já que, a partir dele, cria-se um modelo de consumismo. É necessária a intervenção social na elaboração de uma nova consciência que deixe de valorizar a mulher a partir do corpo e passe a projetá-la no mundo como ser político e ideológico.

Embora a educação seja um processo permanente que transcende o espaço e o tempo escolar, a escola é uma das territorialidades onde ocorre parte do desenvolvimento humano e, portanto, é um território fértil para problematizar culturas e reinventar novos discursos que empoderem as minorias, sobretudo as mulheres. A escola é um dos espaços onde os sujeitos deixam de ser indivíduos e passam a constituir uma coletividade. Nesse contexto, cumpre associar diferentes ações educativas que propiciem o diálogo entre as gerações. É o conhecimento sistematizado e orientado que possibilita a troca, já que a perspectiva pluricultural no 
âmbito da educação sofre resistência devido às ideologias dominantes que perpassam os espaços escolares e os discursos oficiais.

Assim, percebe-se que é fundamental as comunidades escolares adquirirem consciência de que a organização racional do mundo foi estabelecida sob uma ideologia de dominação, de modo que um grupo cria para si uma hegemonia em detrimento de populações imensas, cujos lugares sociais, de subalternidade estão, por assim dizer, predeterminados. Desconstruir essa realidade posta, abrindo novos horizontes para uma vivência mais harmoniosa e justa tem sido a bandeira do feminismo. Entretanto, a medida que os movimentos se fortalecem nas ruas, dentro das casas a violência também cresce por razões inúmeras, inclusive porque as mulheres se tornaram mais independentes.

Pesquisas do IBGE publicadas em 2014 ${ }^{1}$ no Portal Brasil apontam que 87,4\% das famílias sem cônjuge é chefiada por mulheres e, os dados da SIS (Síntese de Indicadores Sociais), mostram que de 2004 a 2014 subiu de 3,6\% para 15,1\% o número de famílias formadas por casais e filhos cuja responsabilidade econômica é atribuída às mulheres. Esses percentuais apontam que, embora os homens ainda sejam predominantemente os chefes de família, as mulheres têm assumido cada vez mais a responsabilidade econômica, o que nos leva ao entendimento de que elas estão mais inseridas no mundo do trabalho e das produções de bens de consumo. No que se refere à renda dos brasileiros, os registros de 2014 mostram que as mulheres ganham até $75,4 \%$ dos rendimentos do cônjuge, sendo que 37,2\% recebem até 50\% menos dos rendimentos do companheiro. A fatia de mulheres que recebem até um salário é de 30,6\% e de homens é de $21,5 \%$. Os dados levam a compreensão de que há uma real necessidade de se pensar em estratégias para promover a formação política das mulheres, pois a luta, nesse caso, passa a ser pela sobrevivência.

Outro dado interessante é o Coeficiente de Gini, também utilizado para medir o índice de desigualdade social. De acordo com essa estatística, a distribuição de rendimento médio mensal de todos os trabalhos por sexo no Brasil está menos desigual, sendo o,491 entre homens com ocupação e o,474 entre mulheres com ocupação. O que existe hoje são as dificuldades de acesso à oferta de formação e qualificação profissional e cidadã que respeitem as peculiaridades e dificuldades das mulheres, pois, para sobreviver nesse campo de batalhas, elas realizam tripla jornada de trabalho, ou seja, além da atividade laboral de subsistência, cuidam dos filhos, da casa e muitas ainda são responsáveis pelo cuidado dos familiares mais idosos. Essa realidade revela que a população feminina sofre o desprivilegio por estarem em condições desiguais em relação aos homens. É importante observar que essa fatia da população está mais concentrada nas periferias, de onde falam as minorias.

Diante do contexto, esta proposição deve abranger a população feminina na faixa etária acima de 18 anos, que busca oportunidades de acesso às ações educacionais e à inclusão e permanência no mundo do trabalho, tendo como ponto

1 Os índices não haviam sido atualizados até a consulta realizada em dezembro/2019. 
central a identificação, reconhecimento e valorização da diversidade e dos saberes acumulados em cada uma de suas etapas de vida.

Esta proposição de formação é significativa para o público esperado, porque é criada de acordo com a identificação da experiência não-formal adquirida pela mulher ao longo da vida e de acordo com os seus anseios pessoais e profissionais, construindo-se um itinerário formativo personalizado. Dessa forma contribui para a ampliação do acesso à educação, visando à formação para o desenvolvimento pessoal e profissional. Para isso, é necessário planejar conhecimentos básicos que subsidiem a compreensão de saberes necessários para a formação técnica.

O debate sobre as desigualdades se estende para quase todos os espaços sociais. A arte, enquanto linguagem que expressa as subjetividades do ser humano e da natureza, sempre foi uma medida para conhecermos os níveis de desigualdade de um povo. Na obra de arte há discursos de resistência, há representações da dor, da luta, metáforas das violências. A arte busca na vida elementos que a ressignifiquem, que narrem com verossimilhança ou que narrem sob uma perspectiva outra, como a vida poderia ser. A arte ecoa a realidade.

Muitos são os exemplos, nesse sentido, na América Latina. As perturbadoras telas de Frida Kahlo; as personagens de Clarice Lispector, com seus corpos comportados e suas atitudes que causam epifania no leitor; as maravilhosas personagens dos contos e crônicas maravilhosos da Marina Colasanti; as intensas pinturas de Liliana Maresca; a visibilidade do trabalho e da produção da mulher feito por Anna Maria Maiolino; a recente série nacional, Coisa mais linda, produzida pela Netflix; enfim, cada obra na qual sobressaem os abusos que as mulheres sofrem tenta divulgar para o público o modo como essa sociedade concebe as relações. A arte também ecoa discursos pela igualdade de gênero.

As mulheres não engendram um projeto de dominação-exploração dos homens, na compreensão de Saffioti (2001), e tal comportamento estabelece uma ampla diferença entre a ideologia masculina e a ideologia feminina. O conceito de dominação-exploração remete ao político e ao econômico como território propício à dominação. As mulheres, pode-se acrescentar, não deseja submeter o homem a uma condição de dominado-explorado. O que querem é lutar pelo lugar da igualdade, não se trata de uma luta pelo poder.

Certamente os movimentos feministas e os estudos feministas ainda têm muito trabalho a desenvolver. Mais do que isso, toda ação que implica a luta pela igualdade de gênero precisa ressignificar as linguagens, as práticas, propor e causar fissuras nas atitudes patriarcais e nos discursos da hegemonia. A dominação é um fenômeno histórico contra o qual as mulheres precisam lutar, precisam desconstruir suas bases mandonistas e, acima de tudo, formular modelos de vivência mais democráticos. 


\section{Referências}

BOURDIEU, Pierre. (2007). A dominação masculina. Trad. Maria Helena Kühner. 5 ed. Rio de Janeiro: Bertrand Brasil.

BRASIL. MinistériodaEducação.Programa Nacional Mulheres Mil-Guia Metodológico. Brasília, s/d.

(2014). Ministério do Planejamento, Orçamento e Gestão; Instituto Brasileiro de Geografia e Estatística. Estatística de Gênero - Uma análise dos resultados do Censo Demográficos 2010. Rio de Janeiro: IBGE. Disponível em <https://www.ibge.gov.br/ apps/snig/vi/?loc=0 >. Acesso em 15/12/2018.

BUTLER, Judith. (2010).Problemas de gênero: feminismo e subversão da identidade. Trad. Renato Aguiar, 3 ed, Rio de Janeiro: Civilização Brasileira.

CAMPOS, Maria Consuelo Cunha. (1992).“Gênero”. In: Jobim, José Luís (org.). Palavras da crítica. Rio de Janeiro: Imago Editora, p.11-126.

FGV. Fundação Getúlio Vargas. Violência conta a mulher. Disponível em http://dapp. fgv.br/tudo-sobre/violencia-contra-mulher/. Acesso em 13/o2/2019.

GIULANI, Paola Cappelin. (2001).“Os movimentos de trabalhadoras e a sociedade brasileira”. In: DEL PRIORE, M. (Org.) História das mulheres no Brasil. 5 ed. São Paulo: Contexto, p. 640-667.

OMS - Organização Mundial da Saúde. World Health Statistics 2018. Disponível em $<$ https://apps.who.int/iris/bitstream/handle/10665/272596/9789241565585-eng. pdf?ua $=1 \& u a=1>$ Acesso em 28/03/2019.

ROSALDO, Michelle Zimbalist. (1979). "A mulher, a cultura e a sociedade: uma revisão teórica”. In: A mulher, a cultura e a sociedade. Trad. Cila Ankier e Rachel Gorenstein. Rio de Janeiro: Paz eTerra, p. 33-64.

SAFFIOTI, Heleieth I.B. (2001)."Contribuiç̃oes feministas para o estudo da violência de gênero". In: Cadernos Pagu [online]. Campinas, n.16: p.115-136. Disponível em: $<$ http://www.scielo.br/pdf/cpa/n16/n16ao7.pdf>. Acesso em 22/o1/2019.

SANTOS, Boaventura de Souza. (2013). "Direitos humanos, democracia e desenvolvimento".In: CHAUI, Marilena; SANTOS, Boaventura de Sousa. Direitos humanos, democracia e desenvolvimento. São Paulo: Cortez, p.41-133. 
TIBURI, Marcia. (2018).Feminismo em comum: para todas, todes e todos. Rio de Janeiro: Rosa dos Tempos.

Recebido em 15/04/2019.

Aceito em 12/05/2020. 